\title{
Impacto de la vacuna neumocócica conjugada 13-valente en la incidencia de neumonía consolidante en menores de 5 años en el partido de Pilar, Buenos Aires: estudio de base poblacional
} Impact of the 13-valent pneumococcal conjugate vaccine on the incidence of consolidated pneumonia in children younger than 5 years old in Pilar, Buenos Aires: A population-based study

\author{
Dra. Ángela Gentile , Dra. Julia Bakir ${ }^{a}$, Dra. Laura Bialorus ${ }^{b}$, Dra. Laura Carusoc, \\ Dr. Diego Mirrab , Bioq. Celina Santander ${ }^{b}$, Dra. Mabel Terluk ${ }^{b}$ Dr. Pablo Zurdo ${ }^{b}$, \\ Dr. Fernando Gentile y Dra. María I. Fernández ${ }^{b}$
}

\section{RESUMEN}

Introducción. Enenerode 2012, en Argentina, fue introducida la vacuna neumocócica conjugada 13-valente (13-Valent Pneumococcal Conjugate Vaccine; PCV13, por sus siglas en inglés) en el Calendario Nacional, en menores de 2 años. La cobertura en el partido de Pilar en 2012 fue $>90 \%$ para las primeras 2 dosis y $60 \%$ para la tercera. Objetivo. Medir la efectividad de la PCV13 en la reducción de la incidencia de neumonías consolidantes (NC), durante los dos años siguientes a su introducción en el Calendario. Métodos. Estudioprospectivodebasepoblacional en Pilar. Se incluyeron todos los menores de 5 años con signos clínicos de neumonía atendidos en hospitales de referencia (ambulatorios y hospitalizados) en los primeros 2 años de la incorporación (2012-2013). Se comparó la incidencia anual de NC con el período basal 2003-2005. Evaluación clínica-radiológica, según criterio de la Organización Mundial de la Salud. Resultados. Se incluyeron 666 pacientes con sospecha clínica de neumonía. Se diagnosticó NC en 309 pacientes; $52,1 \%$ de mujeres, $70,2 \%$ menores de 2 años y $56,4 \%$ vacunado con PCV13; $4,5 \%(14 / 309)$ con bacteriología confirmada ( $S$. pneumoniae: 4; N. meningitidis: 4; S. aureus: 2; otros: 4). Se observó una reducción significativa en la incidencia de NC (por 100000 niños menores de 5 años) entre los períodos pre y posvacunal de $750(204 / 27209)$ a $561(171 / 30475)$ en 2012 y 453 (138/30 475) en 2013; efectividad de $25,2 \%$ y $39,6 \%$, respectivamente. Reducción en menores de 1 año: $33,9 \%$ en 2012 y 44,6\% en 2013 ; y en niños de $12-23$ meses: $57,9 \%$ en 2013 . No se observaron diferencias significativas en las incidencias en edades mayores.

Conclusiones. Luego de la introducción de la PCV13 en el Calendario de Vacunación en Argentina, se observó una reducción rápida y significativa en la incidencia de $\mathrm{NC}$, principalmente en menores de 1 año en 2012 y menores de 2 años en 2013.

Palabras clave: Streptococcus pneumoniae, neumonía, vacuna conjugada, efectividad, niño.

http:/ /dx.doi.org/10.5546/aap.2015.502

\section{INTRODUCCIÓN}

Streptococcus pneumoniae es la causa bacteriana más importante de neumonía adquirida en la comunidad (NAC); sin embargo, la carga de neumonía neumocócica es difícil de definir con exactitud, ya que las pruebas diagnósticas de rutina tienen baja sensibilidad. En menos del 10\% de los pacientes hospitalizados por NAC, se aísla el germen en sangre y aumenta el rendimiento del cultivo cuando el paciente presenta empiema y se cuenta con una muestra de líquido pleural. ${ }^{1}$ Es evidente, entonces, que el diagnóstico microbiológico da una visión muy parcial del impacto de S. pneumoniae.

Debido a estas dificultades, la Organización Mundial de la Salud (OMS) elaboró un protocolo basado en la interpretación estandarizada de radiografías de tórax. Propuso medir la efectividad de las vacunas sobre la base de la disminución de las "neumonías consolidantes confirmadas radiológicamente" como un acercamiento razonable a la "neumonía bacteriana". El propósito era estrictamente epidemiológico, de modo de tener una herramienta eficaz que permitiera medir el impacto de la introducción de las vacunas neumocócicas conjugadas a los calendarios nacionales. ${ }^{2}$

En Argentina, se realizó un estudio de base poblacional prospectivo en el partido de Pilar entre los años 2003 y 
2005 (3 años), que permitió obtener datos basales de carga de neumonía consolidante (NC) en niños $<5$ años, que, en promedio, fue de 750 por 100000 (IC 95\%: 650-860) y, en menores de 1 año, fue de 1922 por 100000 (IC 95\%: 1560-2330). ${ }^{3}$

En enero de 2012, fue introducida la vacuna neumocócica conjugada 13-valente (13-Valent Pneumococcal Conjugate Vaccine; PCV13, por sus siglas en inglés) en el Calendario Nacional de Inmunizaciones, a partir de los dos meses de vida con un esquema " $2+1$ " (una dosis a los 2 , otra a los 4 meses y un refuerzo al año de vida). Durante el primer año de introducción, también se vacunaron los niños de entre 12 y 24 meses, con un esquema de dos dosis para lograr un mayor impacto en el menor tiempo posible en la disminución de las enfermedades neumocócicas invasivas en el país. ${ }^{4}$ Las coberturas nacionales de la PCV13 del año 2012 fueron del 69\% para la primera dosis y del $22 \%$ para la tercera dosis $\mathrm{y}$, en el año 2013, fueron del 96\% y del 81\%, respectivamente. ${ }^{5}$ La cobertura en el partido de Pilar, calculada mediante registros nominales, fue para un total de 6735 recién nacidos vivos en el año 2012 del 100\%, 83\% y 48,3\% para la $1^{\text {ra }}, 2^{\text {da }}$ y $3^{\text {era }}$ dosis, respectivamente. ${ }^{6}$ Para el año 2013 fue del $87,6 \%, 84,9 \%$ y $61,3 \%$, respectivamente. ${ }^{7}$

\section{OBJETIVO}

Medir la efectividad de la PCV13 en la reducción de neumonías consolidantes durante los dos años siguientes a su introducción en el Calendario Nacional.

\section{MÉTODOS \\ Población}

El partido de Pilar se encuentra a $54 \mathrm{~km}$ al noroeste de la provincia de Buenos Aires y, según el Censo Nacional de Población de 2010, tiene una población de 299077 habitantes, de los cuales 30475 (10,2\%) son menores de 5 años de edad. Estos constituyeron la población en seguimiento.

\section{Criterios de inclusión}

Todos los niños < 5 años con signos clínicos de neumonía, atendidos en forma ambulatoria y hospitalizados, entre el $1^{\text {ro }}$ de enero de 2012 y el 31 de diciembre de 2013, en los hospitales de referencia del Partido de Pilar (2 públicos: Hospital de Niños Federico Falcón, Hospital Juan Sanguinetti; y 1 privado: Hospital Universitario Austral). El algoritmo de la Figura 1 muestra cómo se procedió para el diagnóstico de neumonía consolidante.

\section{Algoritmo operacional}

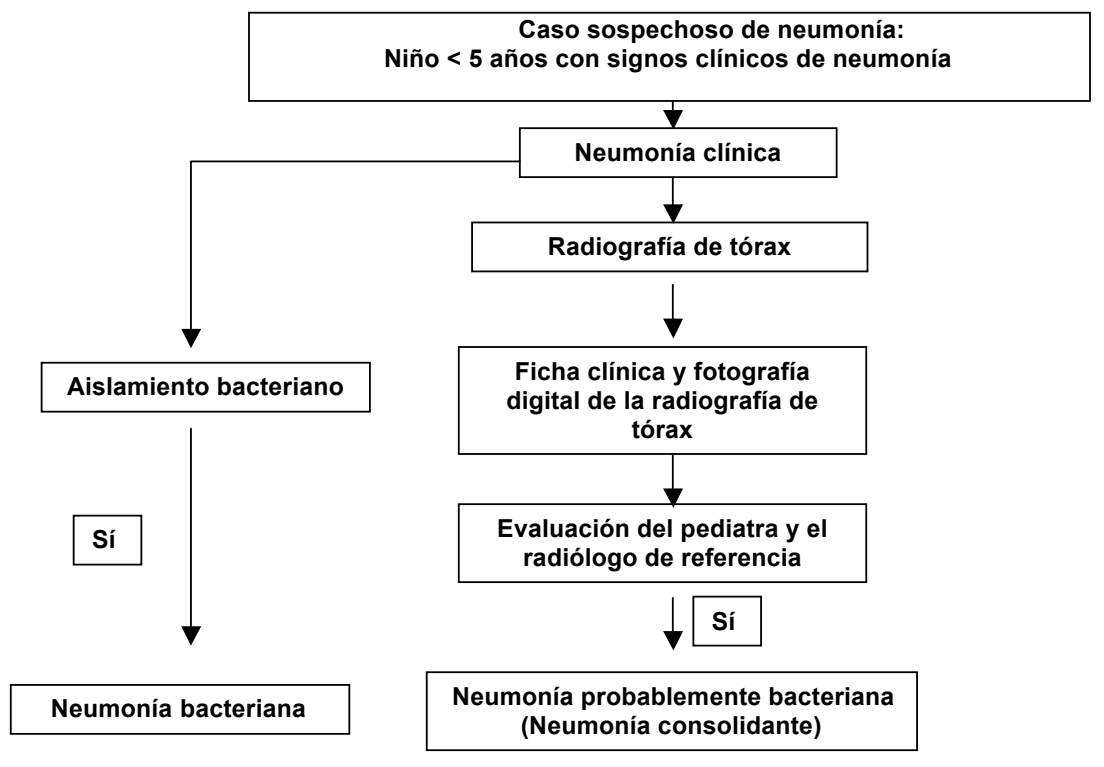




\section{Criterios de exclusión}

Se excluyeron los pacientes con neumonías nosocomiales; según la OMS, definidas como aquellas que no se habían manifestado ni estaban en período de incubación, es decir, que se adquirieron durante la internación y no eran la causa del ingreso. ${ }^{8}$

\section{Diseño}

Estudio prospectivo de base poblacional, después de la introducción de la PCV13 en el año 2012 en el Calendario Nacional de Vacunación.

\section{Recolección de datos}

Los datos fueron obtenidos de las historias clínicas de los pacientes atendidos tanto en forma ambulatoria como hospitalizados que cumplían los criterios de inclusión. Los datos relevantes se resumieron en una ficha estandarizada, que incluía edad, sexo, nivel socioeconómico según el puntaje de Graffar modificado, ${ }^{9}$ antecedente de vacunación neumocócica (tipo de vacuna y número de dosis), convivencia con más de 5 personas en la misma casa y con más de 3 personas en la misma habitación, internaciones previas, antecedentes perinatológicos, presencia de enfermedades subyacentes, tratamiento antibiótico en los 3 meses previos y en la semana previa al ingreso, signos y síntomas respiratorios seleccionados, complicaciones, tratamiento y evolución.

Como enfermedades subyacentes, se consideraron las referidas en las recomendaciones nacionales de vacunación neumocócica para huéspedes especiales. ${ }^{10}$ Asimismo, se investigaron otras condiciones de riesgo, como tabaquismo pasivo y enfermedad respiratoria aguda en la semana previa.

Como complicaciones, se consignaron derrame, neumotórax, atelectasia, neumonía necrotizante, absceso e insuficiencia respiratoria.

\section{Estudio microbiológico}

Se realizó un estudio microbiológico solo en los pacientes internados. La etiología bacteriana se investigó en la sangre y/o el líquido pleural. Se realizó una punción pleural cuando existía indicación terapéutica de toracocentesis.

Los aislamientos de S. pneumoniae fueron remitidos al Instituto Nacional de Enfermedades Infecciosas (INEI), Administración Nacional de Laboratorios e Institutos de Salud (ANLIS) “Dr. Carlos G. Malbrán" para la confirmación de la identificación y la serotipificación por reacción de quellung. El estudio de la susceptibilidad antimicrobiana fue realizado por el método de difusión en agar y por concentración inhibitoria mínima (CIM) mediante el método de microdilución en caldo o en agar o por E-test, según estándares del Clinical Laboratory Standards Institute (CLSI) vigente. ${ }^{11}$

La etiología viral se investigó según el criterio clínico del pediatra tratante. Se utilizó el método diagnóstico rápido por inmunofluorescencia indirecta (IFI) en aspirados nasofaríngeos para buscar los siguientes virus respiratorios: virus respiratorio sincicial (VRS), adenovirus, influenza A y B, y parainfluenza 1, 2 y 3 .

\section{Evaluación radiológica}

Se realizó una foto digital a las radiografías de tórax, las cuales fueron interpretadas por el pediatra investigador y el radiólogo de referencia en forma ciega e independiente siguiendo la metodología de la OMS. La discrepancia fue resuelta a través de una tercera lectura.

\section{Definición de neumonía consolidante}

Aquella que presenta una imagen densa, de aspecto algodonoso (infiltrado alveolar), que compromete uno o más segmentos o lóbulos pulmonares o un pulmón completo.

TABla 1. Población estudiada: comparación pre y pos introducción de la vacuna neumocócica conjugada 13-valente

\begin{tabular}{|c|c|c|c|c|}
\hline \multirow[t]{2}{*}{ Población incluida según el algoritmo } & \multicolumn{2}{|c|}{$\begin{array}{c}\text { Período pre-PCV13 } \\
(2003-2005)\end{array}$} & \multicolumn{2}{|c|}{$\begin{array}{c}\text { Período pos-PCV13 } \\
(2012-2013)\end{array}$} \\
\hline & $\mathbf{n}$ & $\%$ & $\mathbf{n}$ & $\%$ \\
\hline Total de pacientes con sospecha clínica de neumonía & 1220 & 100,0 & 666 & 100,0 \\
\hline Casos sospechosos de neumonía c/ foto digital de radiografía de tórax & 1108 & 90,8 & 642 & 96,4 \\
\hline Casos de neumonía consolidante & 611 & 55,1 & 309 & 48,1 \\
\hline Casos de neumonía consolidante bacteriana & 15 & 2,5 & 14 & 4,5 \\
\hline Casos de neumonía consolidante neumocócica & 7 & 1,2 & $4^{*}$ & 1,3 \\
\hline
\end{tabular}

PCV13: vacuna neumocócica conjugada 13-valente.

Sin diferencias significativas entre ambos períodos.

* 2012: $n=2 ; y$ 2013: $n=2$. 
Frecuentemente, presenta el broncograma aéreo y, en algunas ocasiones, se asocia a derrame pleural.

\section{Análisis de datos}

El análisis estadístico se realizó con el programa Epiinfo, versión 6.4 (CDC, Atlanta), y el programa Epidat, versión 3.1.

Las variables cualitativas se expresaron en términos de porcentaje y se analizaron con el test $\chi^{2}$ con corrección de Yates. Para describir las variables numéricas, se utilizó la media, el desvío estándar (DE), la mediana y el rango.

Se calculó la incidencia anual de casos de NC y el promedio de incidencia anual del período previo a la vacunación con IC 95\%. La diferencia entre las incidencias pre y posvacunación se expresó como efectividad calculando el porcentaje de reducción con un IC 95\%.

Se consideró significativa una probabilidad menor de 0,05 .

\section{Aspectos éticos}

En esta investigación, no se solicitó consentimiento informado por tratarse de un estudio de vigilancia. Contó con la aprobación del Comité de Ética en Investigación del hospital incluido.

\section{RESULTADOS}

\section{Población estudiada según el algoritmo} operacional

Durante los dos años de vigilancia posteriores a la introducción de la PCV13, se incluyeron 666 pacientes con sospecha clínica de neumonía.

El 96,4\% (642/666) de las radiografías fueron fotografiadas, y se diagnosticó NC en el 48,1\% (309/642). En la Tabla 1, se presenta la población incluida en este período y en el previo a la vacunación con PCV13.

TABLA 2. Características de la población con neumonía consolidante: comparación pre y pos introducción de la vacuna neumocócica conjugada 13-valente

\begin{tabular}{|c|c|c|c|c|c|c|}
\hline \multirow[t]{2}{*}{ Características } & & \multicolumn{2}{|c|}{$\begin{array}{l}\text { Período pre-PCV13 } \\
2003-2005(n=611)\end{array}$} & \multicolumn{2}{|c|}{$\begin{array}{l}\text { Período pos-PCV13 } \\
2012-2013(n=309)\end{array}$} & \multirow[t]{2}{*}{$\mathrm{p}$} \\
\hline & & $\mathrm{n}$ & $\%$ & $\mathrm{n}$ & $\%$ & \\
\hline Tipo de atención & $\begin{array}{l}\text { Ambulatoria } \\
\text { Hospitalizado }\end{array}$ & $\begin{array}{l}139 \\
472\end{array}$ & $\begin{array}{l}22,7 \\
77,3\end{array}$ & $\begin{array}{c}84 \\
225\end{array}$ & $\begin{array}{l}27,2 \\
72,8\end{array}$ & NS \\
\hline Sexo & Masculino & 337 & 55,2 & 148 & 47,9 & 0,04 \\
\hline Edad & $\begin{array}{l}0-23 \text { meses } \\
24-59 \text { meses }\end{array}$ & $\begin{array}{l}448 \\
163\end{array}$ & $\begin{array}{l}73,3 \\
26,7\end{array}$ & $\begin{array}{c}217 \\
92\end{array}$ & $\begin{array}{l}70,2 \\
29,8\end{array}$ & NS \\
\hline Nivel socioeconómico & $\begin{array}{l}\text { Alto } \\
\text { Mediano } \\
\text { Bajo }\end{array}$ & & & $\begin{array}{c}63 \\
181 \\
65\end{array}$ & $\begin{array}{l}20,4 \\
58,6 \\
21,0\end{array}$ & \\
\hline \multicolumn{2}{|c|}{ Más de 5 personas que conviven en la casa } & \multicolumn{2}{|c|}{ NE } & 108 & 35,0 & \\
\hline \multicolumn{2}{|c|}{ Más de 3 personas en la misma habitación } & \multicolumn{2}{|c|}{ NE } & 50 & 16,2 & \\
\hline \multicolumn{2}{|l|}{ Enfermedad subyacente } & 284 & 46,5 & 182 & 58,9 & $<0,01$ \\
\hline \multicolumn{2}{|c|}{ Enfermedad respiratoria crónica o recidivante } & 214 & 35,0 & 130 & 42,1 & 0,04 \\
\hline \multicolumn{2}{|l|}{ Desnutrición } & 31 & 5,1 & 8 & 2,6 & NS \\
\hline \multicolumn{2}{|c|}{ Antecedente de prematurez } & \multicolumn{2}{|c|}{ NE } & 40 & 12,9 & \\
\hline Antibiótico previo & $\begin{array}{l}\text { En los } 3 \text { meses previos } \\
\text { En la semana previa }\end{array}$ & $\begin{array}{l}69 \\
47\end{array}$ & $\begin{array}{l}11,3 \\
7,7\end{array}$ & $\begin{array}{l}34 \\
18\end{array}$ & $\begin{array}{l}11,0 \\
5,8\end{array}$ & $\begin{array}{l}\text { NS } \\
\text { NS }\end{array}$ \\
\hline \multicolumn{2}{|l|}{ Internaciones previas } & 143 & 23,4 & 84 & 27,2 & NS \\
\hline \multicolumn{2}{|c|}{ Enfermedad respiratoria aguda en la semana previa } & \multicolumn{2}{|c|}{ NE } & 52 & 16,8 & \\
\hline \multicolumn{2}{|l|}{ Tabaquismo pasivo } & \multicolumn{2}{|c|}{ NE } & 127 & 41,1 & \\
\hline Síntomas & $\begin{array}{l}\text { Tos } \\
\text { Fiebre } \\
\text { Taquipnea } \\
\text { Tiraje } \\
\text { Dificultad respiratoria } \\
\text { Dificultad para alimentarse } \\
\text { Sibilancias } \\
\text { Vómitos } \\
\text { Cianosis }\end{array}$ & $\begin{array}{l}605 \\
485 \\
593\end{array}$ & $\begin{array}{l}99,0 \\
79,4 \\
97,0\end{array}$ & $\begin{array}{c}284 \\
277 \\
251 \\
135 \\
238 \\
132 \\
94 \\
72 \\
61\end{array}$ & $\begin{array}{l}91,9 \\
89,6 \\
81,2 \\
43,7 \\
77,0 \\
42,7 \\
30,4 \\
23,3 \\
19,7\end{array}$ & $\begin{array}{l}<0,01 \\
<0,01 \\
<0,01\end{array}$ \\
\hline
\end{tabular}

NS: diferencia no significativa.

NE: no evaluado.

PCV13: vacuna neumocócica conjugada 13-valente. 


\section{Descripción de la población de pacientes con neumonías consolidantes}

De la población de pacientes con NC $(n=309)$, la mediana de edad fue de 13 meses (rango: 0-59 meses); 70,2\% eran menores de 2 años (de los cuales $47,6 \%$ eran menores de 1 año). El 62,9\% $(107 / 170)$ de los niños < 2 años que concurrió con carnet estaba vacunado con PCV13; el 43,9\% (47/107) recibió una dosis; el 42,6\% (42/107), segunda dosis; y el 16,8\% (18/107), tercera dosis. Siete pacientes habían recibido PCV7 antes de la introducción de la PCV13 al Calendario. En términos generales, no se observaron diferencias significativas en las características evaluables de la población de pacientes con NC entre ambos períodos (Tabla 2).

\section{Síntomas y evolución clínica de los pacientes con neumonías consolidantes}

Los síntomas más frecuentes en los pacientes con NC fueron tos, fiebre y taquipnea, al igual que en el período prevacunal, aunque con diferencias significativas (Tabla 2). El $26,7 \%(60 / 225)$ de los pacientes con NC internados presentó complicaciones, que, en orden de frecuencia, fueron (de un total de 78 complicaciones registradas) derrame $(38,5 \%)$, insuficiencia respiratoria $(25,6 \%)$, atelectasia $(15,4 \%)$, neumotórax/bullas $(11,5 \%)$, neumonía necrotizante $(5,1 \%)$ y absceso pulmonar $(3,9 \%), y$ la letalidad fue del $0,9 \%(2 / 225)$.

\section{Diagnóstico microbiológico}

Se efectuaron estudios bacteriológicos en el $99,6 \%$ de los pacientes con NC hospitalizados $(224 / 225)$. En todos ellos, se realizaron hemocultivos y, en cuatro pacientes, cultivo de líquido pleural. Se identificó etiología bacteriana en 14 pacientes $(6,3 \%)$ : S. pneumoniae (4), $S$. aureus (2), N. meningitidis (4) y otras bacterias en 4 pacientes, lo que resultó en un tasa de NC bacteriana confirmada del 4,5\% (14/309).

Los serotipos de $S$. pneumoniae $(\mathrm{n}=4)$ fueron $23 \mathrm{~F}, 4$, 7F (serotipos incluidos en la vacuna) y uno parcialmente tipado: 27, 32 o 41 (las infecciones producidas por estos serotipos correspondieron a 2 pacientes no vacunados y a 2 con esquema incompleto por la edad $<12$ meses). Todas las cepas de $S$. pneumoniae fueron sensibles a la penicilina.

Solo en 51 pacientes con NC internados se realizó IFI en aspirado nasofaríngeo; fueron positivos $34(66,7 \%)$ : VRS $(73,5 \%)$, virus parainfluenza $(14,7 \%)$, adenovirus $(5,9 \%)$ y virus influenza $(5,9 \%)$. Dos pacientes presentaron infecciones mixtas ( 1 caso con $S$. pneumoniae más VRS y otro con $S$. agalactiae más VRS).

\section{Impacto de la vacuna neumocócica conjugada 13-valente}

Se observó una reducción significativa en la incidencia de NC (por 100000 niños $<5$ años) luego de la introducción de la vacuna en relación con el período de referencia prevacunal. Al ajustar por edad, se evidenció una reducción mayor en los menores de 12 meses en 2012 y aún más en 2013, mientras que el grupo de 12-23 meses demostró una reducción significativa recién en 2013, segundo año de la intervención (Tabla 3).

No se observaron diferencias significativas en las incidencias en edades mayores.

TABLA 3. Incidencia de neumonía consolidante según el grupo etario. Efectividad de la vacuna neumocócica conjugada 13-valente

\begin{tabular}{|c|c|c|c|c|c|c|c|c|c|c|}
\hline \multirow{4}{*}{ Grupos de edad } & \multirow{2}{*}{\multicolumn{3}{|c|}{$\begin{array}{c}\text { Período pre-PCV13 } \\
2003-2005\end{array}$}} & \multicolumn{7}{|c|}{ Período posvacunación } \\
\hline & & & & & & 2012 & & & & 13 \\
\hline & \multirow{2}{*}{$\begin{array}{l}\text { Población } \\
\text { en riesgo }^{\mathrm{a}}\end{array}$} & $\mathrm{n}$ & Incidencia $^{\mathrm{b}}$ & \multirow{2}{*}{$\begin{array}{l}\text { Población } \\
\text { en riesgo }{ }^{c}\end{array}$} & \multirow{2}{*}{$\mathrm{n}$} & \multirow{2}{*}{$\begin{array}{l}\text { Incidencia }^{\mathrm{b}} \\
\text { (IC } 95 \%)\end{array}$} & \multirow{2}{*}{$\begin{array}{l}\text { Efectividad } \\
\% \text { (IC 95\%) }\end{array}$} & \multirow[t]{2}{*}{$\mathrm{n}$} & \multirow{2}{*}{$\begin{array}{l}\text { Incidencia }^{\mathrm{b}} \\
\text { (IC 95\%) }\end{array}$} & \multirow{2}{*}{$\begin{array}{l}\text { Efectividad } \\
\% \text { (IC } 95 \% \text { ) }\end{array}$} \\
\hline & & \multicolumn{2}{|c|}{ Promedio (IC 95\%) } & & & & & & & \\
\hline Menores de 5 años & 27209 & 204 & $750(650-860)$ & 30475 & 171 & $561(480-650)$ & $25,2(8,3-38,9)$ & 138 & $453(380-530)$ & $39,6(25,0-51,3)$ \\
\hline 0-11 meses & 5324 & 102 & $1922(1560-2330)$ & 6314 & 80 & $1267(1000-1580)$ & $33,9(11,6-50,5)$ & 67 & $1061(820-1350)$ & $44,6(24,6-59,3)$ \\
\hline $12-23$ meses & 5046 & 47 & $931(680-1240)$ & 6113 & 46 & $752(550-1000)$ & 19,2 (NS) & 24 & $393(250-580)$ & $57,9(31,1-74,2)$ \\
\hline 24-59 meses & 16839 & 54 & $321(240-420)$ & 18048 & 45 & $249(180-330)$ & 22,3 (NS) & 47 & $260(190-350)$ & 18,8 (NS) \\
\hline
\end{tabular}

${ }^{a}$ Censo 2000.

${ }^{\mathrm{b}}$ Incidencia por 100000 personas/año.

${ }^{\mathrm{c}}$ Censo 2010.

NS: diferencia no significativa.

PCV13: vacuna neumocócica conjugada 13-valente. 


\section{DISCUSIÓN}

En Argentina, según el último informe del Ministerio de Salud (diciembre de 2012), la enfermedad respiratoria fue la tercera causa de mortalidad infantil (luego de las afecciones perinatales y las anomalías congénitas) y constituyó $8,6 \%$ de las muertes totales del período, lo que representa 764 niños menores de 5 años fallecidos en el año 2011. ${ }^{12}$

La neumonía, una de las formas de enfermedad neumocócica, causó casi 1 de cada 5 muertes en niños menores de 5 años a nivel mundial: más de 1,6 millones de niños cada año, según estimaciones basadas en datos del año $2000 .{ }^{13}$ Reducir la mortalidad asociada a la enfermedad por S. pneumoniae es esencial si la comunidad internacional desea alcanzar los Objetivos del Milenio (ODM), en particular el ODM 4 (reducir globalmente la mortalidad infantil). La posición oficial de la OMS consiste en que debe priorizarse la implementación de la vacunación neumocócica en todos los programas nacionales de vacunación, sobre todo en países que tienen una alta mortalidad infantil.

En el caso de la enfermedad neumocócica, las vacunas conjugadas confieren inmunidad contra S. pneumoniae en niños pequeños y pueden proteger indirectamente a miembros no inmunizados dentro de la comunidad (que incluyen a niños no vacunados) a través de un "efecto de inmunidad comunitaria" o "efecto rebaño", basado en la reducción de la transmisión del agente infeccioso por parte de individuos inmunizados.

A partir de fines de la década del 90, se desarrollaron varios estudios de incidencia de las NAC en países de Latinoamérica, que han servido como línea basal para medir la efectividad de la intervención en los respectivos países. Los estudios de Uruguay, Brasil y Argentina han presentado resultados similares en cuanto a la incidencia de la NC. . $^{3,14-16}$

Los datos de Pilar han sido utilizados como línea basal en este estudio para medir la importancia de la intervención posterior, en este caso, la vacunación.

Al analizar las características disponibles de la población estudiada pre y posintervención, a pesar de los años transcurridos, no se observan diferencias estadísticamente significativas, por lo que podemos decir que no hay sesgos en el tipo de población estudiada. Sin embargo, la ubicación geográfica del área bajo vigilancia podría considerarse una debilidad del estudio: la población de Pilar está muy cerca de la Ciudad de Buenos Aires y puede ser que algunos niños hayan sido atendidos fuera del partido de Pilar, por lo que la tasa de incidencia señalada podría haber sido, entonces, menor que la real. Esto es válido para los dos períodos de estudio, pre y pos introducción de la vacuna 13-valente, por lo que no se invalidan los resultados.

Los síntomas de consulta de los niños incluidos en el estudio, tos, fiebre y taquipnea, fueron los habituales en este tipo de patología, una tríada que el pediatra está habituado a reconocer, que se encuentra presente en toda la literatura sobre el tema y que marca la gravedad de estos pacientes en el momento de la evaluación clínica. ${ }^{1,17,18}$

Si bien en todos los pacientes hospitalizados se efectuó la búsqueda del agente etiológico mediante hemocultivos y/o cultivo de líquido pleural, es importante destacar la baja recuperación obtenida: tan solo en el 4,5\% se pudo reconocer etiología bacteriana documentada. Esto permite reflexionar nuevamente sobre la importancia de un indicador alternativo, la incidencia de neumonía consolidante, propuesta por la OMS/Organización Panamericana de la Salud (OPS) para medir la efectividad de estas vacunas neumocócicas conjugadas en la prevención de las neumonías. $^{2}$

Otro punto que merece mencionarse es el rol de los virus en la etiología de las neumonías consolidantes. Solo se ha estudiado el 22,7\% de los casos hospitalizados por NC, debido a dificultades programáticas, y que, de hecho, podría considerarse una debilidad del estudio. Sin embargo, estos datos marcan la importancia del rol del VRS en la etiología de estas formas clínicas. ${ }^{19}$ Ya estudios de la bibliografía internacional y en Latinoamérica muestran también el rol del virus influenza en la etiología de estas formas clínicas. ${ }^{14,20,21}$ Queda pendiente una mayor investigación sobre los casos de coinfeccion virus-bacteria.

Los datos de efectividad muestran un importante descenso en la magnitud de la enfermedad: la incidencia de neumonía consolidante disminuyó un 33,9\% y $44,6 \%$ en los menores de un año en 2012 y 2013, respectivamente. Este efecto se da fundamentalmente porque las coberturas de vacunación en el partido de Pilar fueron muy buenas en ese grupo de edad; alcanzaron más del $80 \%$ en las dos primeras dosis.

Este efecto se observa en el grupo de 1 a 2 años recién en el segundo año del estudio y está 
en relación directa con las coberturas alcanzadas en el área. Al ser aún estos porcentajes no tan elevados como se supone, no podemos ver el "efecto rebaño" en los mayores de dos años. Este efecto de la vacunación neumocócica conjugada en niños no vacunados en el marco del programa regular o en edades no alcanzadas por la vacuna permitiría esperar una reducción aún mayor si las coberturas fueran superiores al $80 \%$ en la población objetivo. ${ }^{4}$

Los trabajos de Hortal y de Andrade tanto en Uruguay como en Brasil, respectivamente, muestran resultados similares. En Uruguay, se obtuvo una reducción del $44,9 \%$ en la incidencia de neumonías consolidantes en el grupo de 12 a 23 meses con igual metodología que la instrumentada en el partido de Pilar, con coberturas de vacuna neumocócica 13-valente de alrededor del $92 \% .{ }^{22}$

En Brasil, con el uso de la vacuna conjugada neumocócica 10-valente (Pneumococcal Nontypeable Haemophilus influenzae Protein D Conjugate Vaccine; PHiD_CV, por sus siglas en inglés), se observó una reducción significativa para neumonía en Belo Horizonte (28,7\%), Curitiba $(23,3 \%)$ y Recife $(27,4 \%)$, pero no en San Pablo y Porto Alegre, lugares en los cuales la reducción no fue significativa, posiblemente porque las coberturas de vacunación no fueron tan elevadas. ${ }^{23}$

Es importante generar investigaciones epidemiológicas en el país con información propia para medir las acciones implementadas y ajustar las estrategias de acuerdo con los datos locales. Además, la difusión de la información generada y analizada en un área del país puede estimular a otros centros y jurisdicciones a realizar también análisis de situaciones locales.

\section{CONCLUSIÓN}

Luego de la introducción de la PCV13 en el Calendario Nacional de Vacunación de Argentina, se observó una reducción rápida y significativa en la incidencia de neumonía consolidante, fundamentalmente en niños menores de 1 año en 2012 (año de la incorporación), que se amplió a todo el grupo de menores de 2 años en 2013.

\section{REFERENCIAS}

1. Comité de Infecciones Respiratorias de la Sociedad Latinoamericana de Infectología Pediátrica (SLIPE). Consenso de la SLIPE sobre Neumonía Adquirida en la Comunidad (NAC). Rev Enfer Infec Pediatr 2010;24(94):3-23. [Acceso: 17 defebrerode 2014]. Disponibleen:http:/ / www. slipe.org/pdf/ConsensoNACninosSLIPE_8sept2010.pdf.
2. World Health Organization Pneumonia Vaccine Trial Investigators' Group. Department of Vaccines and Biologicals. Standardization of interpretation of chest radiographs for the diagnosis of pneumonia in children. Geneva, 2001. [Acceso: 1 de julio de 2015]. Disponible en: http://whqlibdoc.who.int/hq/2001/WHO_V\&B_01.35. pdf.

3. Gentile A, Ruvinsky R, Bakir J, Gentile F, et al. Surveillance of Probably Bacterial Pneumonia in children less than 5 years old in two geographical areas in Argentina. Abstract of the 45th Interscience Conference on Antimicrobial Agents and Chemotherapy. Washington DC, 2005; G-822 236.

4. Argentina. Ministerio de Salud. Introducción de la Vacuna Conjugada contra el Neumococo alCalendario Nacional de Inmunizaciones de la República Argentina. Lineamientos Técnicos y Manual del Vacunador. Buenos Aires: Ministerio de Salud de la Nación, 2011. [Acceso: 1 de julio de 2015]. Disponible en: http://www.msal.gov.ar/neumococo/ descargas/lineamientos-neumococo-25-11-2011.pdf.

5. WHO. WHO vaccine-preventable diseases: monitoring system. 2015 global summary Coverage time series for Argentina. [Acceso: 1 de marzo de 2015]. Disponible en: http://apps.who.int/immunization_monitoring/ globalsummary/coverages?c=ARG.

6. Programa de Inmunizaciones. Dirección de Epidemiología. Dirección de Medicina Preventiva. Ministerio de Salud de la Provincia de Buenos Aires Partido de Pilar. Secretaría de Salud. Cobertura de vacuna neumocócica conjugada 13 valente, 2012 (comunicación personal).

7. Dirección Provincial de Medicina Preventiva Región Sanitaria V Área Epidemiología. Ministerio de Salud de la Provincia de Buenos Aires. Cobertura de vacunación en menores de un año, Prevenar 13, según municipios. Año 2013. Boletín Epidemiológico 2013. p 52.

8. Organización Mundial de la Salud. Prevención de las infecciones nosocomiales. Guía Práctica. 2. a ed. Malta, 2003. [Acceso: 12 de abril de 2015]. Disponible en: http:// www.who.int/csr/resources/publications/ES_WHO_ CDS_CSR_EPH_2002_12.pdf.

9. Méndez Castellano H. Sociedad y Estratificación: Método Graffar-Méndez Castellano. Caracas: FUNDACREDESA; 1994.

10. Argentina. Ministerio de Salud. Recomendaciones Nacionales de Vacunación, Argentina 2012. Buenos Aires, 2012. [Acceso: 1 de julio de 2015]. Disponible en: http://www.msal.gov.ar/images/stories/bes / graficos/0000000451cnt-2013-06_recomendacionesvacunacion-argentina-2012.pdf.

11. Clinical and Laboratory Standards Institute. Performance Standards for Antimicrobial Susceptibility Testing; Nineteenth InformationalSupplement(M100-S19). Wayne, PA; 2009 .

12. Argentina. Ministerio de Salud. Secretaría de Políticas, Regulación e Institutos, Dirección de Estadísticas e Información de Salud. Sistema Estadístico de Salud. Estadísticas vitales. Información básica año 2011. Buenos Aires, 2012;5(55). [Acceso: 1 dejulio de 2015]. Disponibleen: http://www.deis.msal.gov.ar/Publicaciones/Archivos/ Serie5Nro57.pdf.

13. World Health Organization. UNICEF. Global action plan for prevention and control of pneumonia (GAPP). [Acceso: $1 \mathrm{de}$ julio de 2015]. Disponible en: http:/ / whqlibdoc.who.int/ hq/2009/WHO_FCH_CAH_NCH_09.04_eng.pdf?ua=1.

14. Hortal M, Estevan M, Iraola I, De Mucio B. A populationbased assessment of the disease burden of consolidated pneumonia in hospitalized children under five years of age. Int J Infect Dis 2007;11(3):273-7. 
15. Andrade AL, Silva SA, Martelli CM, Oliveira RM, et al. Population-based surveillance of pediatric pneumonia: use of spatial analysis in an urban area of Central Brazil. Cad Saude Publica 2004;20(2):411-21.

16. Tregnaghi M, Ceballos A, Rüttimann R, Ussher J, et al. Active epidemiologic surveillance of pneumonia and invasive pneumococcal disease in ambulatory and hospitalized infants in Córdoba, Argentina. Pediatr Infect Dis J 2006;25(4):370-2.

17. Pírez MC, Algorta G, Cedrés A, Sobrero H, et al. Impact of universal pneumococcal vaccination on hospitalizations for pneumonia and meningitis in children in Montevideo, Uruguay. Pediatr Infect Dis J 2011;30(8):669-74.

18. Sociedad Argentina de Pediatría. Comité de Infectología Pediátrica. Libro Azul de Infectología Pediátrica. 4. ${ }^{a}$ ed. Buenos Aires: FUNDASAP; 2012:413-7.

19. Lución MF, Juárez MV, Viegas M, Castellano $V$, et al. Virus respiratorio sincicial. Patrón clínico epidemiológico en niños internados en un hospital pediátrico durante los años 2000-2013. Arch Argent Pediatr 2014;112(5):397-404.

20. Gentile A, Bakir J, Russ C, Ruvinsky S, et al. Estudio de las enfermedades respiratorias por virus Influenza A H1N1 (pH1N1) en niños internados durante el año de la pandemia. Experiencia de 34 centros en la Argentina. Arch Argent Pediatr 2011;109(3):198-203.

21. Juárez MV, Lución MF, BakirJ, Romanin $V$, etal.Efectividad de la vacuna neumocócica de 13 serotipos en menores de 5 años a través de la vigilancia epidemiológica de las neumonías consolidantes y la influencia de los virus respiratorios. Estudio de series temporales 2001-2013. 7. ${ }^{\circ}$ Congreso Argentino de Infectología Pediátrica; 2014, abril 3-5. Córdoba: Sociedad Argentina de Pediatría, 2014. Abstract PO52. p. 78.

22. Hortal M, Estevan M, Laurani H, Iraola I, Meny M, Paysandú/Salto Study Group. Hospitalized children with pneumonia in Uruguay: pre and post introduction of 7 and 13-valent pneumococcal conjugated vaccines into the National Immunization Program. Vaccine 2012;30(33):4934-8.

23. Andrade AL, Oliveira R, Vieira MA, Minamisava R, et al. Population-based surveillance for invasive pneumococcal disease and pneumonia in infants and young children in Goiania, Brazil. Vaccine 2012;30(10):1901-9.

"Entregar mucho de uno mismo.

Saber que, por lo menos, la vida de una persona

ha sido más fácil porque hemos podido ayudarla.

Eso es haber triunfado."

Ralph W. Emerson 